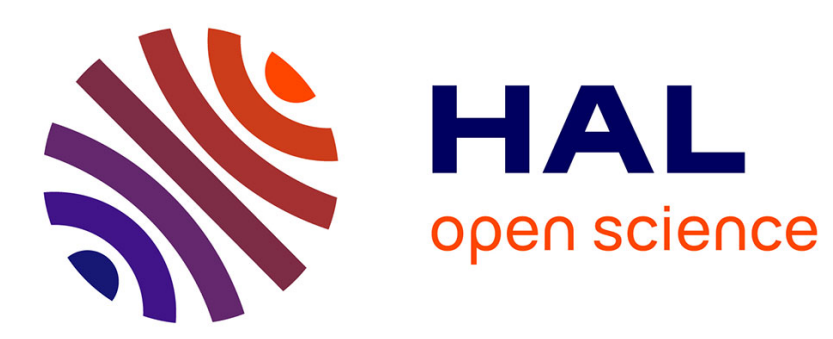

\title{
Stress equilibrium effects within Hopkinson bar specimens
}

D. Parry, P. Dixon, S. Hodson, N. Al-Maliky

\section{To cite this version:}

D. Parry, P. Dixon, S. Hodson, N. Al-Maliky. Stress equilibrium effects within Hopkinson bar specimens. Journal de Physique IV Proceedings, 1994, 04 (C8), pp.C8-107-C8-112. 10.1051/jp4:1994816 . jpa-00253371

\section{HAL Id: jpa-00253371 https://hal.science/jpa-00253371}

Submitted on 1 Jan 1994

HAL is a multi-disciplinary open access archive for the deposit and dissemination of scientific research documents, whether they are published or not. The documents may come from teaching and research institutions in France or abroad, or from public or private research centers.
L'archive ouverte pluridisciplinaire HAL, est destinée au dépôt et à la diffusion de documents scientifiques de niveau recherche, publiés ou non, émanant des établissements d'enseignement et de recherche français ou étrangers, des laboratoires publics ou privés. 


\title{
Stress equilibrium effects within Hopkinson bar specimens
}

\author{
D.J. Parry, P.R. Dixon, S. Hodson and N. Al-Maliky \\ Department of Physics, Loughborough University of Technology, Loughborough, Leics LE11 3TU, U.K.
}

\begin{abstract}
Résumé Dans le split Hopkinson barre technique pour compréssion, un échantillon en forme de disque serré entre deux fastes barres d'acier est compressé par une impulsion compressive. Les proprietés de la contrainte et déformation de l'échantillon peut être dérivé par la quantité d'impulsion compressive, renvoyé et transmit par l'échantillon, en supposant que l'équilibre contrainte existe tout le long de l'échantillon. Néanmoins pendant la période initiale de compression, les multiples réflexions générés aux deux barre/échantillon interfaces creé une distribution compressive non-uniforme, qui arrive à une évaluation peut-être incorrecte des propriétés initials de contrainte/déformation. Cette publication décrit une analyse de microordinateur afin d'étudier plusiers paramètres importants qui influencent l'accumulation de l'équilibre contrainte d'élasticité et prédit les formes d'impulsion reflétés et transmit pour des impulsions de compression différents.
\end{abstract}

Abstract In the compression testing version of the split Hopkinson pressure bar technique a small disc-shaped specimen, sandwiched between two high-strength steel bars, is compressed by a stress pulse. The stress/strain properties of the specimen can be derived from the amount of the stress pulse reflected and transmitted by the specimen, assuming that stress equilibrium exists throughout the specimen. However, during the initial loading phase the multiple reflections generated at the two specimen/bar interfaces cause a non-uniform stress distribution, leading to possibly inaccurate estimates of the initial stress/strain properties. The paper describes a microcomputer analysis to study many of the important parameters affecting the build-up to elastic stress equilibrium and to predict the reflected and transmitted pulse shapes for different loading pulses.

\section{INTRODUCTION}

The split-Hopkinson pressure bar (SHPB) technique is one of the best established methods for determining the high strain-rate properties of materials. The specimen under study is in the form of a stnall solid disc which is sandwiched between two long, high-strength, steel pressure bars (the incident and transmitter bars). A stress pulse of about $100 \mu$ s duration is generated in the incident bar by impacting it axially with a projectile [1]. This pulse travels down the bar and loads the specimen, which reflects part of the pulse and allows the rest to pass into the transmitter bar. Strain gauges on each bar, equidistant from the specimen, record the incident strain $\varepsilon_{\mathrm{v}}$, the reflected strain $\varepsilon_{\mathrm{R}}$, and the transmitted strain $\varepsilon_{\mathrm{T}}$. 


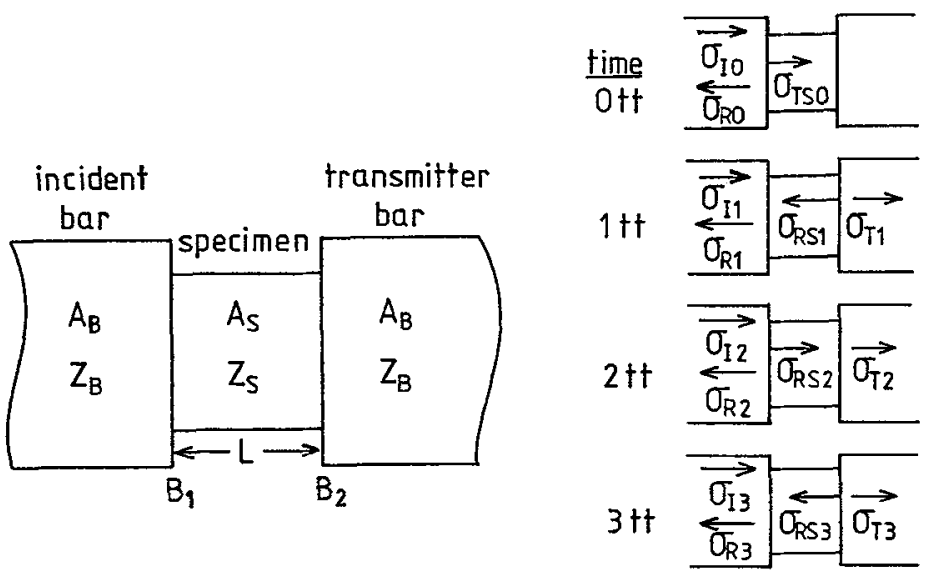

(a)
$\sigma_{T S O}=T_{1} \sigma_{I 0}$
$\sigma_{R 0}=R_{1} \sigma_{I 0}$

$\sigma_{\mathrm{T} 1}=\mathrm{T}_{2} \sigma_{\mathrm{TSO}}=\mathrm{T}_{1} \mathrm{~T}_{2} \sigma_{\mathrm{IO}}$

$\sigma_{R S 1}=R_{2} \sigma_{T S O}=-R_{1} T_{1} \sigma_{I O}$

$\sigma_{\mathrm{R} 1}=R_{\mathrm{I}} \sigma_{\mathrm{I} 1}$

$\sigma_{\mathrm{T} 2}=T_{1} T_{2} \sigma_{\mathrm{I} 1}$

$\sigma_{\mathrm{RS} 2}=R_{2} \sigma_{\mathrm{RS} 1}+T_{1} \sigma_{\mathrm{I} 2}=R_{1}^{2} T_{1} \sigma_{\mathrm{IO}}+T_{1} \sigma_{\mathrm{I} 2}$

$\sigma_{R 2}=R_{1} \sigma_{I 2}-R_{1} T_{1} T_{2} \sigma_{10}$

$\sigma_{\mathrm{T} 3}=T_{2} \sigma_{\mathrm{RS} 2}=T_{1} T_{2} R_{1}^{2} \sigma_{\mathrm{IO}}+T_{1} T_{2} \sigma_{I 2}$

$\sigma_{\mathrm{RS} 3}=R_{2} \sigma_{\mathrm{RS} 2}=-T_{1} R_{1}^{3} \sigma_{10}-T_{1} R_{1} \sigma_{12}$

$\sigma_{R 3}=R_{1} \sigma_{13}-R_{1} T_{1} T_{2} \sigma_{I 1}$

(b)

Figure 1 (a) Pressure bars and specimen;

(b) the build-up of the transmitted and reflected pulses up to the first three traverse times (tt)

SHPB theory shows that the specimen strain $\varepsilon_{\mathrm{s}}$, strain rate $\dot{\varepsilon}_{\mathrm{s}}$ and stress $\sigma_{\mathrm{s}}$ are given by $\varepsilon_{\mathrm{S}}=\left(2 \mathrm{c}_{\mathrm{B}} / \mathrm{L}\right) \int_{\mathrm{o}}^{\mathrm{t}} \varepsilon_{\mathrm{R}} \mathrm{dt}, \dot{\varepsilon}_{\mathrm{s}}=-\left(2 \mathrm{c}_{\mathrm{B}} / \mathrm{L}\right) \varepsilon_{\mathrm{R}}$ and $\sigma_{\mathrm{S}}=\left(\mathrm{A}_{\mathrm{B}} / \mathrm{A}_{\mathrm{s}}\right) \mathrm{E}_{\mathrm{B}} \varepsilon_{\mathrm{r}}$,

where $L, A_{s}$ are the length and cross-sectional area of the specimen, while $c_{B}, A_{B}$ and $E_{B}$ are the wavespeed, cross-sectional area and Young's modulus for each pressure bar. An important assumption made in deriving the equations is that stress equilibrium exists in the specimen. It is clear, however, that especially in the initial phase of loading, the multiple reflections generated at the two specimen/bar interfaces must cause non-uniform stress distribution. An examination of this phenomenon is given in this paper.

\section{COMPUTATIONS}

Figure la shows part of the SHPB system adjacent to a specimen. The acoustic impedance $Z$ is given by $\mathrm{Z}=\rho \mathrm{c}$, where $\rho$ is the density and $\mathrm{c}$ is the wavespeed. For the linear elastic material behaviour appropriate to the early stages of the specimen response, $c_{s}=\left(E_{s} / \rho_{s}\right)^{1 / 2}$, where $E_{s}$ is the Young's modulus of the specimen.

A simple analysis at each interface [2] shows that a stress wave $\sigma_{1}$ incident on the first plane interface $B_{1}$ results in a transmitted stress $\sigma_{\mathrm{T}}$ and a reflected stress $\sigma_{\mathrm{R}}$ given by:

$\sigma_{T}=\left[2 A_{B} Z_{s} /\left(A_{s} Z_{s}+A_{B} Z_{B}\right)\right] \sigma_{I}=T_{1} \sigma_{I}$

$\sigma_{R}=\left[\left(A_{s} Z_{s}-A_{B} Z_{B}\right) /\left(A_{s} Z_{s}+A_{B} Z_{B}\right)\right] \sigma_{\mathrm{I}}=R_{1} \sigma_{Y}$

where $T_{1}, R_{1}$ are the transmission and reflection coefficients, respectively.

At the second plane interface $B_{2}$, the equivalent coefficients for waves going from the specimen into the bar are:

$T_{2}=2 A_{s} Z_{B} /\left(A_{s} Z_{s}+A_{B} Z_{B}\right) ; R_{2}=\left(A_{B} Z_{B}-A_{s} Z_{s}\right) /\left(A_{B} Z_{B}+A_{s} Z_{S}\right)=-R_{1}$

For a compressive incident stress the transmitted stress will always be positive; the reflected stress can be tensile or compressive. Usually $A_{s} Z_{s}<A_{B} Z_{B}$ making $R_{1}$ negative and $R_{2}$ positive.

Figure $1 \mathrm{~b}$ indicates how the multiple reflections between the interfaces cause the build-up of the reflected and transmitted pulses in the pressure bars. Iterative expressions can be derived for the w'th traverse time. 


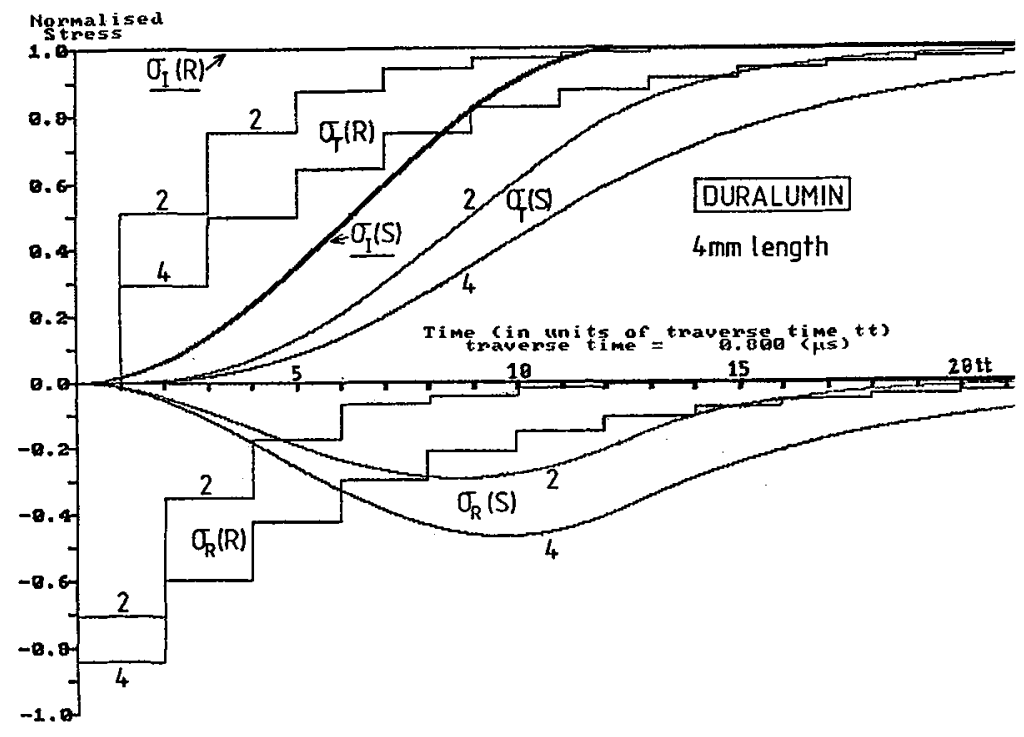

Figure 2 Transmitted and reflected pulse shapes for a Duralumin specimen using rectangular (R) and smooth (S) incident pulses, with bar/specimen area ratios of 2 and 4.

The stress going into the transmitter bar is given by:

$\sigma_{\mathrm{TN}}=\mathrm{R}_{1}^{2} \sigma_{\mathrm{T}(\mathrm{N}-1)}+\mathrm{T}_{1} \mathrm{~T}_{2} \sigma_{\mathrm{I}(\mathrm{N}-1)}$, for $\mathrm{N} \geq 3$

The stress reflected back into the incident bar is given by:

$\sigma_{\mathrm{RN}}=\mathrm{R}_{1}\left(\sigma_{\mathrm{IN}}-\sigma_{\mathrm{T}(\mathrm{N}-1)}\right)$, for $\mathrm{N} \geq 2$

The first few terms for each component are unique and are generated independently. A BASIC program has been written, for an IBM compatible PC, in which the incident pulse can have any shape and is composed of 2500 data points.

\subsection{Results for different incident pulse shapes}

The first incident pulse shape used was a simple rectangular pulse having zero rise and fall times and a flat top. An example is given in Figure 2 of the computer predictions for the reflected $\left(\sigma_{R}\right)$ and transmitted $\left(\sigma_{\mathrm{T}}\right)$ pulses during the first 20 traverse times of loading a $4 \mathrm{~mm}$ long Duralumin specimen. One traverse time in the specimen is $0.800 \mu \mathrm{s}$. (Duralumin: $\rho=2.80 \mathrm{Mg} / \mathrm{m}^{3}, \mathrm{E}=70 \mathrm{GPa}, \mathrm{c}=5000 \mathrm{~m} / \mathrm{s}$; steel pressure bars: $\rho=7.72 \mathrm{Mg} / \mathrm{m}^{3}, E=212 \mathrm{GPa}, \mathrm{c}=5240 \mathrm{~m} / \mathrm{s}$, diameter $=12.7 \mathrm{~mm}$ ). All the stresses are normalised by dividing the pulses by the amplitude of the incident pulse $\sigma_{\mathrm{I}}$. The effect of having two different bar/specimen area ratios of 2 and 4, a typical range for SHPB experiments, is also shown. The stepped change in the pulses every two traverse times is clearly seen, as is the instantaneous start of the reflected (tensile) pulse one traverse time ahead of the transmitted (compressive) pulse. In general, the larger the area ratio the greater is the reflected pulse and the smaller the transmitted.

Using the rectangular pulse gives a good insight into the effect of wave reflections, but does not produce the smooth pulses evident in SHPB tests. A much more realistic representation of the incident pulse is given by using a smooth pulse consisting of a cosine-type rise and fall combined with a flat top. The effects of such a pulse are also shown in Figure 2, with a loading risetime of $10 \mu$ s (typical for SHPB). It can now be seen that much smoother reflected and transmitted pulses result which closely resemble actual SHPB pulses. 


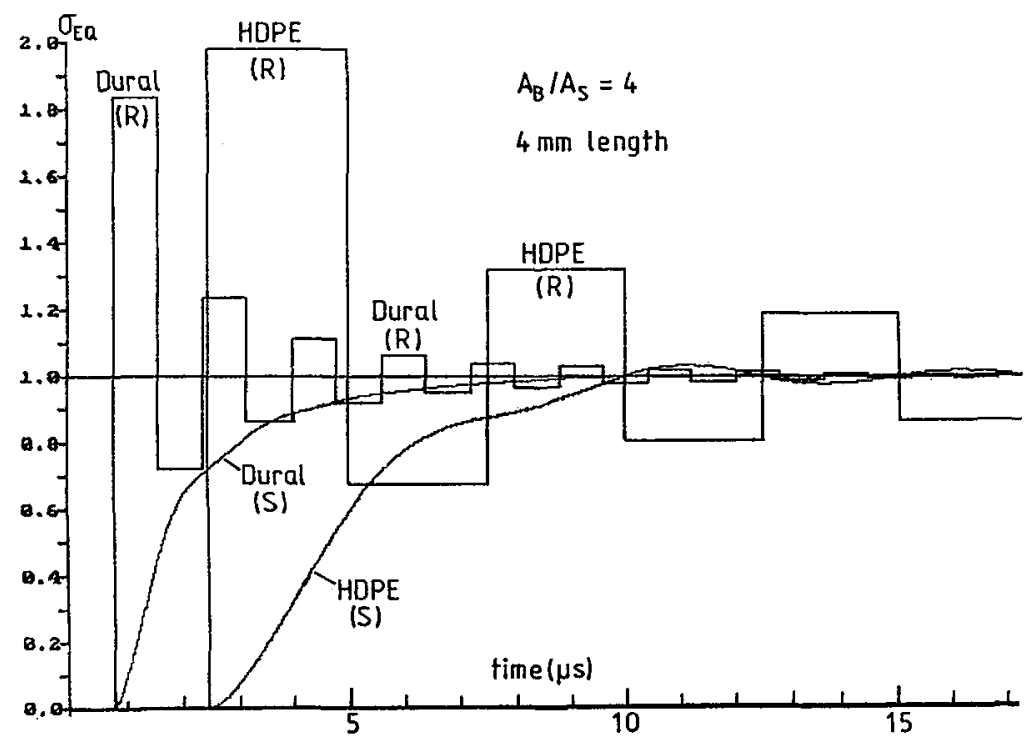

Figure 3 Equilibrium factor $\sigma_{\mathrm{EQ}}$ for $4 \mathrm{~mm}$ length Duralumin and HDPE specimens using rectangular (R), and $10 \mu$ s-risetime smooth $(S)$, incident pulses.

\subsection{Stress equilibrium}

The state of stress equilibrium in the specimen can be observed by comparing the stresses on the faces of the bars in contact with the specimen as a function of time. A 'stress equilibrium factor' $\sigma_{\mathrm{EQ}}$ can be defined as $\sigma_{E Q}=\sigma_{T} /\left(\sigma_{I}+\sigma_{R}\right)$. When this reaches unity there is perfect equilibrium. Figure 3 illustrates how this ratio varies as a function of time for two different materials, each of specimen length $4 \mathrm{~mm}$, with a bar/specimen area ratio of 4 . The high density polyethylene (HDPE) has $\rho=0.93 \mathrm{Mg} / \mathrm{m}^{3}, \mathrm{E}=2.40$ $\mathrm{GPa}, \mathrm{c}=1600 \mathrm{~m} / \mathrm{s}$, and the traverse time $=2.50 \mu \mathrm{s}$.

For both the rectangular loading pulse (R), and the smooth (S), $\sigma_{\mathrm{EQ}}$ is zero until the transmitted pulse starts after one traverse time $(0.800 \mu$ s for the Duralumin, $2.50 \mu \mathrm{s}$ for the HDPE). With the rectangular pulse, $\sigma_{\mathrm{EQ}}$ oscillates about the eventual value of unity, with an obvious change in slope every traverse time. The HDPE takes a much longer time to approach equilibrium than the Duralumin. Using the more realistic smooth loading pulse, with a risetime of $10 \mu$ s, gives a much smoother approach to equilibrium for both materials. There is no overshoot of $\sigma_{\mathrm{EQ}}=1$ for the Duralumin and only a small overshoot for the HDPE. Despite the quite different material properties, there is not now the previous marked difference in the build-up to equilibrium. The Duralumin reaches $90 \%$ of its equilibrium value in about 5 traverse times $(4.0 \mu \mathrm{s})$, while the HDPE reaches $90 \%$ in about 3 traverse times $(7.5 \mu \mathrm{s})$.

\subsection{Comparison with experiment}

The above theoretical predictions have been compared with experimental results (Figure 4). The upper diagrams show the experimental SHPB pulses for specimens of PEEK (polyetheretherketone) and CFC (a quasi-isotropic carbon fibre/thermoplastic composite supplied by $\mathrm{ICI}$ ). The predicted pulses (middle diagrams) used the actual specimen dimensions (about 4 min length by $8 \mathrm{~mm}$ diameter) and a smooth incident pulse of the same shape (omitting any oscillations), amplitude, and duration as the actual pulse. Restricting the amplitude of the actual loading pulse enabled the material response to remain elastic. The 


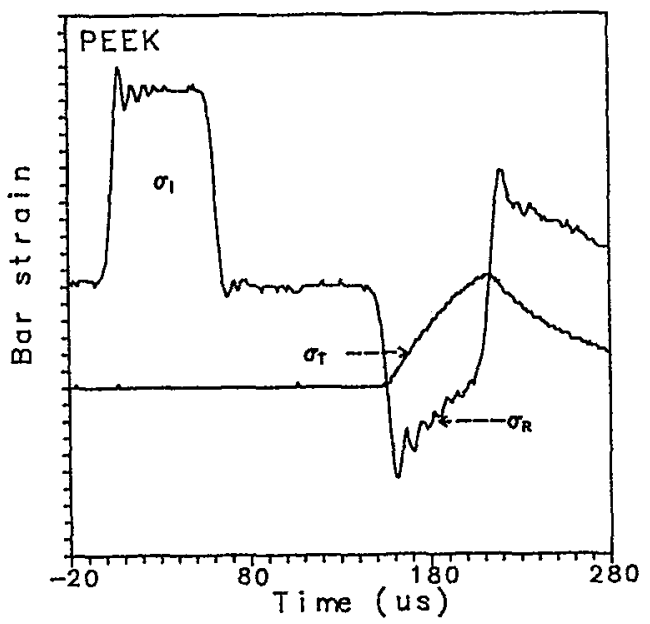

(a)
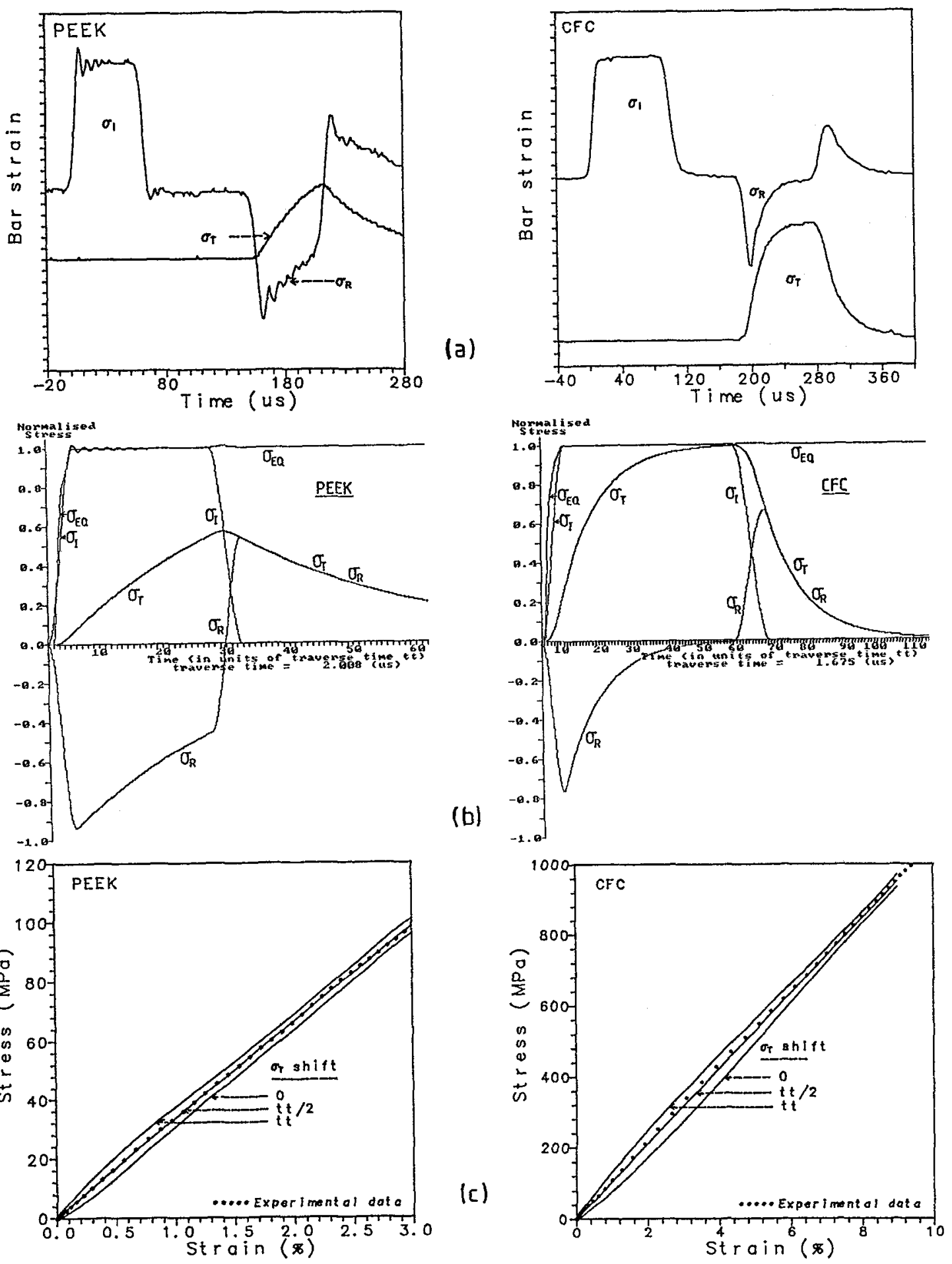

Figure 4 (a) Experimental pulses for PEEK and CFC;

(b) predicted pulses; (c) comparison of theoretical and experimental stress/strain plots 
wavespeed in each specimen was obtained from the experimentally measured Young's modulus (at a strain rate of about $10^{3} / \mathrm{s}$ ).

The predicted pulses are seen to closely resemble the experimental ones. Treating the theoretical plots as experimental traces, a normal SHPB analysis has been carried out, ie ignoring the specimen thickness. This gives the stress/strain curves labelled zero $\sigma_{\mathrm{T}}$ shift in the lower diagrams, which show that the effect of the reflected pulse starting before the transmitted is to cause the initial portions of the plots to have downward curvature. An alternative SHPB analysis of the theoretical plots is to shift the transmitted pulse forward by one traverse time (tt shift) so that it starts at the same time as the reflected. This now produces stress/strain curves with an initial upward curvature. However, if the transmitted stress is shifted forward by half a traverse time ( $1 / 2 \mathrm{tt}$ shift), each stress/strain plot becomes a straight line through the origin, with a constant slope exactly equal to the input Young's modulus. When this $1 / 2 \mathrm{tt}$ shift is used with the SHPB analysis of the experimental traces in the upper diagrams, the results show excellent agreement with the corresponding theoretical stress/strain results. Using the usual SHPB analysis produces results like those for the theoretical zero tt shift, giving an unrealistic low initial slope for the stress/strain behaviour.

\section{DISCUSSION AND CONCLUSIONS}

The theoretical analysis described above has been shown to predict very accurately the shape of the experimental pulses resulting from wave reflections due to SHPB specimens. It also indicates clearly that elastic stress equilibrium is effectively achieved within a specimen after just a few wave reflections, irrespective of the type of material. Several authors have considered the effect of specimen size on the shape of the reflected and transmitted pulses (eg [3], [4] and [5]). However, no detailed analysis of the build-up to stress-equilibrium due to wave reflections was given, except for Briscoe and Nosker [5]. They did a simple analysis using a rectangular loading pulse only, with a specimen of the same crosssectional area as the pressure bars, and obtained a geometric series which could be used to predict the build-up of the stress pulses. Due to the over-simplified nature of the analysis, the results, however, have a very limited application.

The detailed analysis described in the present paper has been used to make accurate predictions of pulse shapes for a wide variety of materials and specimen dimensions, using any required loading pulse profile, and clearly shows how elastic stress equilibrium develops in the specimen.

\section{REFERENCES}

[1] Parry, D J and Walker, A J, IOP Short Meetings Series No 16 (1988) 111-120.

[2] Johnson W, Impact strength of materials (Edward Arnold, London, 1972) pp 35-37.

[3] Bertholf, L D and Karnes, C H, J Mech Phys Solids 23 (1975) 1-19.

[4] Malinowski, J Z and Klepaczko J R, Int J Mech Sci, 28 (1986) 381-391.

[5] Briscoe, B J and Nosker, R W, Wear 95 (1984) 241-262. 